\title{
Desenvolvimento lógico-matemático no ensino de física com o software Scilab
}

\author{
Dellacqua, G. S. ${ }^{1}$; Mothé, R. S. S. ${ }^{1}$; Da Silva, W. B. ${ }^{2}$; Dutra, J. C. S. ${ }^{2}$ \\ 1 Graduação em Engenharia Química, UFES, Alegre, ES, Brasil. \\ 2 Programa de Pós-graduação em Engenharia Química - UFES, Alegre, ES, Brasil.
}

*e-mail: ruthmothe@gmail.com, guilherme.dellacqua@gmail.com.

\begin{abstract}
Resumo
Com a evolução tecnológica no mundo e a necessidade de uma abordagem construtivista que gere fluência tecnológica nos jovens, busca-se a inovação do uso das tecnologias na aprendizagem em distintas áreas. Através desta pesquisa, pretende-se contribuir com o desenvolvimento de uma base lógico-matemática em alunos do Ensino Médio e Fundamental visando dar suporte à aquisição de novos conhecimentos, de acordo com a ideia construtivista conhecida por teoria da assimilação. Além disso, esta pesquisa busca subsidiar a decomposição de problemas do cotidiano em partes simples, identificar e eliminar erros com mais facilidade, desenvolver projetos desde a concepção até a sua concretização, estimular e incentivar o aprendizado de forma cooperativa. Foi visto que a adoção de novos métodos de ensino não só desperta o interesse pelo aprendizado como enriquece as técnicas didáticas e busca atenuar o atraso científico e tecnológico muito presente no sistema educacional atual.
\end{abstract}

\begin{abstract}
With the technological developments in the world and the necessity of a constructivist approach that manages technological fluency in young people, we seek innovation in the use of technology in learning in different areas. Through this research, we intend to contribute to the development of logical-mathematical basis of high school students and Fundamental order to support the acquisition of new knowledge, according to the constructivist idea known as theory of assimilation. Furthermore, this research seeks to support the decomposition of daily problems into simple parts, identify and eliminate errors more easily, develop projects from conception to completion, stimulate and encourage learning cooperatively. It has been seen that the adoption of new teaching methods not only arouses interest in learning but as well enriches the didactic strategies and seeks to attenuate the scientific and technological gap present in the current educational system.
\end{abstract}

Keywords (Palavras chaves):,Scilab,assimilation, constructionism.

\section{Introdução}

Atualmente, as disciplinas, em que o raciocínio lógico é um fator de grande importância, como as que tratam de algoritmos, são encontradas desde os primeiros semestres em cursos superiores da área de Ciências Exatas e Engenharias. Cursá-las com bom aproveitamento tem sido um desafio para os acadêmicos, que enfrentam dificuldades de aprendizagem (Dim e Rocha, 2011). Estas são, em parte, responsáveis pelas reprovações e desistência nestes cursos, de acordo com Raabe e Silva (2005). Uma das causas deste cenário foi apontada por Santos e Costa (2005) e Pereira Júnior et al. (2005) como sendo a falta de uma base lógico-matemática que ajude a desenvolver o raciocínio lógico do aluno.

Segundo as Diretrizes Curriculares Nacionais para o Ensino Médio elaboradas pelo MEC (1998), o desenvolvimento da base lógica-matemática deve ter início ainda no Ensino Médio. Para tanto, foi estabelecido expressamente que as escolas devem organizar seus currículos, de modo a "adotar 
metodologias de ensino diversificadas, que estimulem a reconstrução do conhecimento e mobilizem o raciocínio, a experimentação, a solução de problemas e outras competências cognitivas superiores". Dessa forma, se cumprido este pressuposto, os alunos interessados em um curso superior nas áreas citadas podem ingressar na Universidade com base lógica e raciocínio desenvolvido.

O epistemólogo Jean Piaget introduziu o conceito de construcionismo e suas teorias buscam implantar nos espaços de aprendizagem uma metodologia inovadora que busca formar cidadãos criativos e críticos. De acordo com suas teorias, o professor deve orientar os alunos para a aprendizagem autônoma (Ferrari, 2011). O matemático Seymour Papert introduziu também o conceito de construcionismo, que é uma reconstrução teórica a partir do construtivismo piagetiano (REF.). Papert concordou com Piaget de que a criança é um "ser pensante" e construtora de suas próprias estruturas cognitivas, mesmo sem ser ensinada. Ele se inquietou com a pouca pesquisa nessa área e levantou a seguinte interrogação: Como criar condições para que mais conhecimento possa ser adquirido por esta criança?

Portanto, no intuito de potencializar o ensino, as ferramentas computacionais são essenciais, pois materializam o conhecimento e seduzem as crianças. A criança, que interage com a informática através da lógica de programação, consegue aprender relações matemáticas pela experiência e constrói seu próprio caminho por meio de desafios. Dessa forma, desenvolve habilidades para fazer coisas novas e diferentes e ultrapassar dificuldades, tendo assim meios para satisfazer seus desejos, preparar-se para a sociedade de informação e deixar de ser um consumidor de produtos para ser um protagonista de sua educação (Valente, 1993).

\section{Materiais e métodos}

Visando fomentar maior interesse e aptidão por disciplinas da área de Ciências Exatas nos alunos do Ensino Fundamental da Escola XXXX, iniciou-se um projeto que conta com a utilização de ferramentas computacionais na descrição de problemas simples de Física. Foram escolhidas duas equações desta disciplina para a aplicação de um algoritmo que pudesse levar os alunos a compreender o fundamento por trás das fórmulas.

O software adotado no desenvolvimento da pesquisa, o Scilab (versão 5.5.2), é um instrumento científico para computação numérica distribuído gratuitamente via Internet. Esta ferramenta fornece um poderoso ambiente computacional aberto para aplicações científicas, podendo ser usado como um terminal matemático interativo. É atualmente empregado em diversos ambientes industriais e educacionais pelo mundo.

Os exercícios aplicados a um grupo de $Y Y$ alunos possuíram como conteúdo a Mecânica Cinemática (Movimento Retilíneo Uniforme e Movimento Uniformemente Variado) e a Calorimetria (Calor Sensível e Calor Latente) para que estes relembrassem os referidos conteúdos da disciplina estudados anteriormente e bastante utilizados no dia a dia. As questões propostas foram:

1) Ao iniciar uma viagem partindo de Alegre, a quilometragem do seu carro está em $50.000 \mathrm{~km}$. Chegando em Vitória, 3 horas depois, a quilometragem marca $50.150 \mathrm{~km}$. Qual a velocidade média durante a viagem? Se na BR-101 há multa para quem ultrapassa $70 \mathrm{~km} / \mathrm{h}$, você seria multado se fizesse todo o percurso com velocidade igual à encontrada anteriormente? Supor que você não freia ao ver o radar e nem acelere em retas e que a velocidade é constante por toda a viagem.

2) Se ao chegar em Cachoeiro com velocidade de $80 \mathrm{~km} / \mathrm{h}$, você se depara com um radar e leva 3 segundos para reduzir até $60 \mathrm{~km} / \mathrm{h}$. Qual foi sua aceleração durante o percurso? Como provar que você está freando?

3) Uma fonte de calor aquece $12 \mathrm{~kg}$ de gelo a $-3 \stackrel{\circ}{\circ}$ até que ele vire vapor a $120^{\circ} \mathrm{C}$. Quanto de calor foi fornecido para que o gelo tornasse vapor? Crie um vetor com as temperaturas e as quantidades de calor e utilize o laço FOR-END para cálcular o calor total.

\section{Equacionamento e implementação}

\subsection{Equações}

Do movimento uniforme, pode-se empregar a equação da velocidade média:

$$
\mathrm{Vm}=\frac{(\mathrm{d} 1-\mathrm{d} 0)}{(t 1-t 0)}
$$

Do movimento uniformemente acelerado, tem-se a equação da aceleração média:

$$
\mathrm{am}=\frac{(\mathrm{V} 1-\mathrm{V} 0)}{(t 1-t 0)}
$$

Da calorimetria, vem a equação para o cálculo do calor sensível, em que $\mathrm{T}(\mathrm{i})$ e $\mathrm{T}(\mathrm{i}-1)$ referem-se às posições de um vetor com i valores para a temperatura $T$ :

$$
Q s=m . c .[(T(i)-T(i-1)]
$$

Ainda da calorimetria, tem-se a equação para o cálculo do calor latente, sendo $L o$ calor necessário à mudança de estado físico:

$$
Q l=m . L
$$


As unidades adotadas na resolução dos problemas seguiram o sistema internacional (SI).

\subsection{Algoritmos}

A resolução dos problemas propostos pode ser visualizada nas Figuras 1 a 3 , nas quais se encontram os algoritmos de resolução implementados no software.

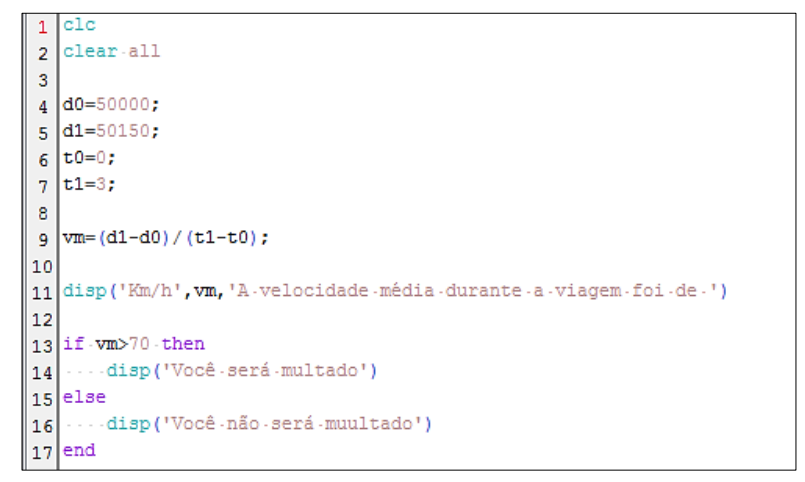

Figura 1: Algoritmo implementado na resolução do Problema 1.

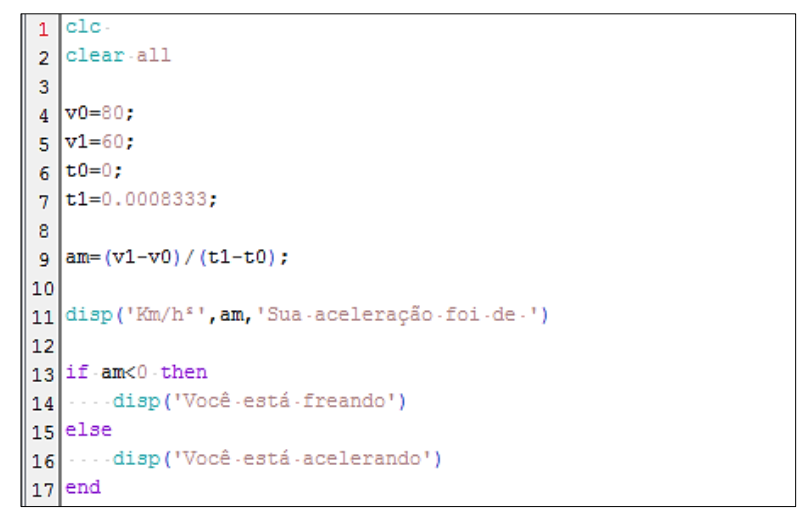

Figura 2: Algoritmo implementado na resolução do Problema 2.

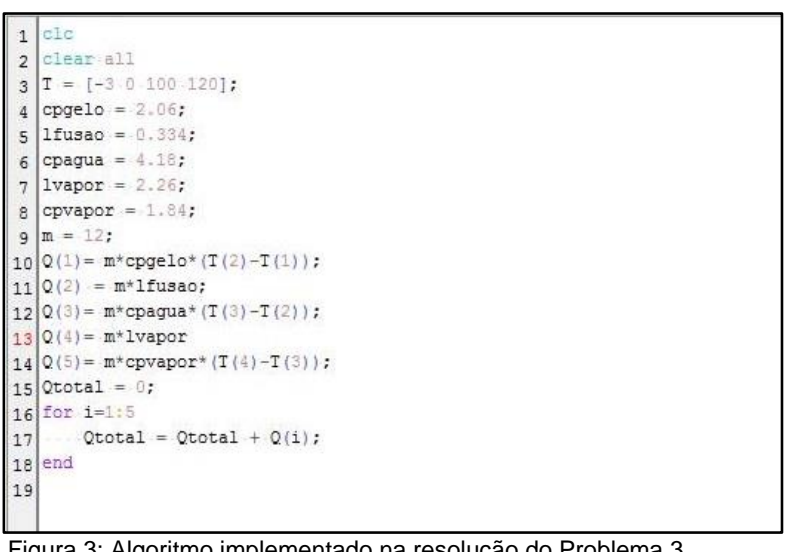

Figura 3: Algoritmo implementado na resolução do Problema 3.

\section{Resultados e discussão}

Para a resolução das questões propostas, utilizaram-se operações básicas como adição, divisão e multiplicação. Necessitou-se também que os alunos se atentassem à regra dos parenteses e à utilização correta da definição das variáveis e dos valores declarados no vetor temperatura. $\mathrm{Na}$ implementação das respostas teóricas, utilizaram-se comandos específicos da programação, tais como as funções IF, ELSE, FOR e DISP.

Interligando o uso do software com a resolução de problemas trabalhados em sala de aula, observou-se que os alunos foram capazes de melhor compreender os assuntos tratados devido ao fato de assimilarem o projeto com suas disciplinas. Além disso, a utilização da programação para solucionar problemas trabalhados em salas de aula e já conhecidos pelos alunos, ajudam estes a compreender melhor as comandos da programação, os quais geralmente são extremamente abstratos para novatos em programação.

\section{Conclusões}

A interface homem-máquina inserida na realidade escolar dos alunos permitiu despertar maior interesse por disciplinas do ensino superior, como a programação. Neste sentido, atividades experimentais bem planejadas e executadas podem induzir o pensamento lógico dos alunos, pois deslocam os mesmos de sua rotina habitual. As aulas deixam de ser meramente descritivas e se tornam situações nas quais os discentes podem implementar o que tenham conjeturado, explorando assim seus conhecimentos. Dessa forma, os alunos são induzidos a relacionar as leis e as teorias aprendidas com suas experiências diárias e usando de críticas podem interpretar e explicar a realidade que os rodeia.

\section{Agradecimentos}

Os autores do presente trabalho agradecem a FAPES pelo apoio financeiro ao projeto e ao grupo de pesquisa LAMCES por ceder o laboratório de informática para que os alunos ministrassem as aulas na UFES.

\section{Referências}

[1] DIM, C. A.; ROCHA, F. E. L. APIN: Uma Ferramenta Para Aprendizagem de Lógicas e Estímulo do Raciocínio e da Habilidade de Resolução de Problemas em um Contexto Computacional no Ensino Médio. In: XXI Congresso da Sociedade Brasileira de Computação, 2011, Natal. XXI Congresso da Sociedade Brasileira de Computação, 2011.

[2] MARTINS, F. M.; QUADROS, A. R. Potencializando a aprendizagem da lógica com uso de ambiente de programação de alto nível. 2012. Trabalho de Conclusão de Curso (Graduação em Sistemas de Informação) Faculdade Meridional.

[3] FERRARI, M. (2011) "Jean Piaget - Educar para Crescer" disponível 
http://educarparacrescer.abril.com.br/aprendizagem/jean -piaget-307384.shtml, Setembro.

[4] MEC. (1998) Ministério da Educação. Conselho Nacional de Educação. Diretrizes Curriculares Nacionais para o Ensino Médio - Resolução CEB/CNE № 3, de 26 de junho de 1998.

[5] PAPERT, S. (1994) "A Máquina das Crianças: Repensando a escola na era da informática (edição revisada)", nova tradução de Paulo Gileno Cysneiros. Porto Alegre, RS: Editora Artmed, 2007 (1 $1^{\text {a }}$ edição brasileira 1994; edição original EUA 1993).

[6] PEREIRA JÚNIOR, J. C. R.; RAPKIEWICZ, C. L.; DELGADO, C.; XEXEO, J. A. M. (2005) "Ensino de Algoritmos e Programação: Uma Experiência no Ensino
Médio." In: XIII Workshop sobre Educação em Computação, São Leopoldo/RS.

[7] RAABE, A. L. A.; SILVA, J. M. C. (2005) "Um Ambiente para Atendimento às Dificuldades de Aprendizagem de Algoritmos." In: XIII Workshop sobre Educação em Computação, São Leopoldo/RS.

[8] ROCHA, P. S.; FERREIRA, B.; MONTEIRO, D.; NUNES, D. S. C.; GOÉS, H. C. N. (2010) "Ensino e Aprendizagem de Programação: Análise da Aplicação de Proposta Metodológica Baseada no Sistema Personalizado de Ensino." In: RENOTE - Revista Novas Tecnologias na Educação, Vol 8, N 3.

[9] VALENTE, J. (1993) "Computadores e conhecimento: repensando a educação", em NIED - Núcleo de Informática Aplicada à Educação, Campinas: UNICAMP. 